\title{
A Bouquet of Development Interventions to achieve Academic success
}

\author{
Mrs. Sunayna Iqbal \\ (Banasthali Vidyapith University, India)
}

\begin{abstract}
This study aims at presenting a bouquet of development interventions which shall help improve the academic achievement of high school students. Often educators complain that students are not motivated to learn; parents echo this cry and each blame the other for the students' apathetic response to learning. If schools and parents focused and developed meaningful programs, across the home and classroom such as mentoring, academic counseling, goal setting, skill enhancement workshops, possible gains could result. The total sum of the effects of all these factors determines the heights of the students' academic achievement. Different researchers have elaborated the relationship of each factor contributing towards academic success of high school students. This study shall aim to present a 12 module package for academic achievement. The study shall shed light on the significance of adopting well defined and result oriented development interventions to improve the all round development of students, which in turn shall reflect on their academic results.
\end{abstract}

Keywords- Academic success, Aptitude testing, Career Counseling, Development Interventions, Personal Development Planning.

\section{Introduction}

The significance of education in shaping the future generations is unarguable. Education, over the years has attained an enviable position in the top priority list of governments, communities, families and societies at large. Education is a very costly project for nations and individual families. Therefore, it is very crucial to understand the factors affecting its provisions and the performance of learners.

The quality of an education programme is measured in terms of the academic performance of the students which in turn is indicated by the achievement scores. Though achievement scores can indicate the results, it cannot indicate the causes of these results-reasons for an outstanding or poor performance, nor suggest the ways for improving the achievement. Therefore there is a need to identify and analyze the factors that can affect academic performance. The understanding of these factors can suggest some measures for improving the quality of education. One such determinant of academic performance is the development interventions which the students undergo during the course of their academic learning.

As a student trainer who has worked very closely with the student, teacher and parent community, I wanted to list down the modules which would form an effective development intervention bouquet for adolescents in their march to success and achievement of their goals.

\section{Personal Development Planning}

In order to implement development interventions, the first step to be taken is PDP. PDP is a process that enables you to reflect on your own learning, performance and achievement and helps you to plan your personal, educational and career development [1]. It is a self-reflection tool in which one gives a thought to how well he is doing currently, what are his strengths, how can he do better, what further skills does he need to develop and what activities should he engage in to get closer to his goals. The basis of such a programme is that the process of reflecting on what and how you learn, reviewing your work and skills and being organized about your personal development, can have a positive impact upon your academic performance. Once the skills and attitudes possessed by a student are identified, the school can define the development interventions that have to be undertaken to take each student closer to his goals. Why do we need such a programme as part of the curriculum? The universities and schools in the west have opened up to the significance of this concept called Personal development planning (PDP). Hence it is high time we smelt the coffee and woke up to the imminent need for self analysis through PDP and development interventions as part of our curriculum.

\section{Need For Development Interventions}

Development interventions seemed particularly beneficial to middle and high school students. As Entwisle [2] revealed, enhancing and highlighting new abilities and academic successes seems essential. Most elementary students begin their academic career with a desire to learn and with an intrinsic approach to achievement. It has been revealed that an intrinsic orientation toward education switches to a more extrinsic orientation as students increase in age [3]. Parents and educators often blame each other for the students' 
apathetic response to learning. Often educators complain that students are unmotivated to learn; parents echo this cry .If schools and parents focused on the different parts of academic motivation and developed meaningful programs, across the home and classroom, possible gains could result [4]. Adolescents appear to be especially vulnerable to threats to their self-esteem. The current research synthesis suggests that they may also be especially responsive to interventions designed to strengthen it. Studies on the characteristics of higher achieving students reveal that such students are likely to have the following characteristics: positive feelings about their school experiences; attribute their success in high school to such things as hard work, self-discipline, organization, ability, and high motivation; tend to watch relatively little television during the school week; tend to associate with students who also were successful in school; and are avid readers [5]. If a student's academic enablers are in need of intervention, there are multiple strategies that can be implemented. Four such strategies include modeling, coaching, behavioral rehearsal, and reinforcement. Ideally, the behavior patterns and daily routines of successful students are taken as models, the students are briefed about this model that is adopted, they are made to incorporate this model in their everyday life and once the desired changes start appearing, measures are taken to reinforce this model.

\section{What Does This Bouquet Aim To Achieve?}

As a student trainer who has worked very closely with the student, teacher and parent community, I wanted to list down the modules which would form an effective development intervention bouquet for adolescents in their march to success and achievement of their goals. The primary objectives of such a programme would be:

- To foster and strengthen reading and writing habits

-To enhance public speaking and presentation skills.

-To shed light on the significance of setting short term and long term goals

-To establish a productive relationship with an adult role model (MKO-More Knowledgeable Other) through mentoring

-Aptitude testing which would enable the student and his parents to understand the aptitude of the student and what he is best suited for

-Career counseling which follows aptitude testing and facilitates goal setting in terms of the student's career life -Time management: to make the best possible use of the time available

-Stress management which would enable the ward to handle stress effectively, derive energy from such situations and channelize it to his advantage throughout his life.

-Understanding one's learning style; differentiating between visual, kinesthetic and auditory learning styles and analyzing what works best for each one of them.

-Memory techniques to enhance/strengthen the wards memorizing abilities and to do away with notes and prompting.

-Academic coaching in which both the schools and the parents have an equal role to play. The schools can introduce the accelerated learning techniques modules as part of academic coaching.

- To keep the students in tune with the developments in ICT (Information and Communication Technology) by including it into the academic modules of schools.

\section{The Modules}

Let us now analyze each of the above mentioned modules in terms of their significance, popularity and effect on the academic achievement of students of today's world.

1.1. Reading and writing habits: Reading, comprehension and writing skills are most important for student's academic performance. If these skills are below the average skill level at their age, then specific interventions becomes a must, in the absence of which, the child would start finding it increasingly difficult to read and understand most subjects like science, history etc and even the word problems in math especially in high school. What a middle school student learns understands and synthesizes in the classroom sets them up for the academic demands in high school. Speed reading is a must have module in every high school curriculum. The basic objective is to increase the rate /speed at which a person reads. What he/she reads in 90 minutes shall be brought down to 30 minutes $\left(1 / 3^{\text {rd }}\right.$ the time) after undergoing a speed reading course. Is it just the reading rate? No. Comprehension is given adequate weightage here. As students are made to read documents one after the other, with the time consumed being recorded in each case. They are made to answer questions based on these passages to test their comprehension. It would be interesting to note that faster you read, the better you comprehend as the rate of distractions are minimized. The different methods employed includes skimming, Meta guiding, elimination of sub vocalization and chunking. U.S.Presidents like John.F.Kennedy, Jimmy carter underwent speed reading courses and advocated the same for their staff.

Apart from increasing the reading rate and comprehension, a student's deficiency/inability, if any, to match up to the grade level speed can be identified through this exercise. 
An overwhelming number of instructors and teachers are of the opinion that writing skills are critical to academic success. Needless to say, writing ability is also highly prized by employers.

"Good writing makes a good student"- Dr Leon Burnett, Dean of Faculty of Humanities and Comparative Studies, University of Essex.

A programme to improve writing skills introduced as part of the curriculum should include workshops on how to structure an essay, parts of speech, punctuation and grammar, improvement of vocabulary, appropriate use of metaphors, avoiding generalizations, avoiding misquoting, proper structuring and referencing techniques etc. 1.2. Public Speaking and Presentation Skills: This is en extension of reading and writing skills as only a student who is an avid reader and can express his thoughts and ideas through written words would be able to articulate his ideas in front of an audience. These three skills go hand in hand and have utmost significance in today's competitive world where group discussions, debates and interviews are around every corner. A high school pass out who is not 'groomed' well with these skills might find the outer world too competitive to survive. A school would take pride in a handful of students who would take the school's name to greater heights in prestigious competitions-this is not acceptable anymore. Instead, every student of the school needs to be groomed to take on the challenges paused by this world and that has to be made the objective of each school.

With public speaking forums aplenty, this would not be a Herculean task for a school. The beginning can be initiated within each class where students have to be briefed about the basic speaking models, etiquette and structures. An attempt which can start off within the classroom can then slowly be taken out to a section and the whole school. Guidelines as to how to go about it and what kind of modules should the student go through before he reaches the finest ways of public speaking can be borrowed from popular speaking forums like toast masters, gavel clubs, youth leadership workshops etc.

1.3. Goal Setting: As the age old adage goes, 'The smartest students are not always the best students'. In fact, certain students of average intelligence excel academically because they have developed short and long term goal-setting skills. If we learn the effective principles of goal-setting, we might be able to improve our academic performance while reducing the amount of time we devote to study. A successful student is one that has a clear understanding of what he/she wants to accomplish for any given task. Each task, however big or small it may be, has to be broken down into minor tasks with time limits and measurable results.

More than 400 co-relational and experimental studies provide evidence for the validity of the goal-setting approach [6], [7]. The basic premise is simple: Explicitly setting goals can markedly improve performance at any given task. Students with clear goals appear more able to direct attention and effort toward goal-relevant activities and away from goal-irrelevant activities. Further more, this works in loops. When a student experiences goal attainment, this increases his self efficacy which motivates him to set higher and more challenging goals, increase his commitment towards attainment of these goals and increases the mobilization of all his resources towards goal attainment.

Goal setting at the school level can be practiced by encouraging students to set long term goals in terms of their life's ambitions and career dreams and short term goals in terms of daily, weekly, monthly and half yearly action plans to perform their academic requirements.

Given the paucity of successful interventions for improving academic performance in students, personal goal setting deserves greater attention as an effective technique for improving academic success.

1.4. More knowledgeable other: Neither the family atmosphere nor the school atmosphere in today's world has provisions for a child to have qualitative conversations with an adult. The knowledge, information, sharing of life's experiences, understanding of people over the years etc is no more handed over from one generation to the other. Who has the time?! But, I am sure; all of my readers would agree the undeniable need for such exchanges with a child. Youth need caring and consistent relationships with adults in order to navigate their way through adolescence and beyond. This concept of having a more knowledgeable other (MKO) is the latest to be added to the essentials of a child's development plan. An MKO can be anyone from a child's own parents, teacher, senior friend, a well meaning neighbor, the members of a parent- student body in schools etc. Such interactions are found to address several risk factors like alienation, academic failure, low commitment to school, and association with delinquent and violent peers. Introducing protective factors including opportunities for prosocial involvement and development of skills for pro-social involvement, bonds with adults, healthy beliefs, and clear standards for behavior would also be carried out through such productive relations. Evaluation of a number of community based mentoring programmes reveal that the existence of such consistent, well supervised and long term relationships with adults can bring about a wide range of positive behavioral changes in students, especially those in their teen ages. School based and community based mentoring programmes in which students are mentored by an MKO has gained wide popularity. As one prominent research report put it, "different children and communities have different needs that neither option can fully address alone . . . using both strategies is likely the best way for programs and funders to reach a wide, diverse group of youth and volunteers" [8].

1.5. Aptitude testing: These are examinations which aim to identify and measure specific set of skills possessed by an individual, such as, intellectual, motor, verbal comprehension, general reasoning, numerical 
operations, perceptual speed or mechanical knowledge etc. Apart from measurement of existing skills, aptitude testing helps to measure his ability to acquire those which he does not possess through future training. Different categories of aptitude tests are administered in the high schools in the west. The most popular one being the Scholastic Assessment Test. Due to increased awareness in this field, many schools have started implementing them in their high school classes. Apart from schools, such tests are now being offered by private organizations and welfare bodies in this part of the world.

Once the basic skills possessed by a child are identified, it becomes easier for him as well as his parents to give a direction to his career dreams. If a child's dream career is found to be a practical possibility in terms of the skills he possess, he is a lucky one. If not, he is still at an advantage, as he would now be made aware of the skills he needs to acquire to fulfill his career dreams.

"My child is born to fulfill my unfulfilled dreams". This thought drives most of the career decisions which the child is forced to take after his high school. Such aptitude tests have reduced such baseless decisions to a great extent as now, we as parents know what our child is best suited for and what he/she doesn't have an aptitude for. 1.6. Career Counseling: Ambitious? Yes. Motivated? Yes. But today's youth is generally considered directionless when it comes to achieving their goals. Goals are set, they have the motivation and are ambitious, but are clueless when it comes to what direction they should turn to. This is mainly because of the lack of coherent plans to achieve their goals. Career guidance can provide students with the necessary tools to set career goals, and give them an understanding of the education and skills they need to meet their goals. This includes trained professionals counseling students on their academic plans, for course-taking while in secondary school as well as for senior school education. The preliminary to a career counseling session shall be an aptitude test which the student has to appear. Based on the results of this aptitude test and in alignment with the goals and dreams of the child as far as possible, these professionals would recommend the career options open before him/her. This includes imparting information about which course to opt for, the universities/colleges which provide these courses, the relevance of such courses and degrees in the job market, the fee structure and every bit of any other information that a student and his family needs to base their decision on. This finally gives a direction to the student rather than a blurred path before him.

1.7. Time Management: The significance of time management in academic success is a given. How well one can utilize the $24 \mathrm{hrs}$ available to him greatly determines his success, not only academically, but throughout his life. The most repeatedly heard complaint from parents of high school students is that they waste their time and do not use it productively. Apart from concentrating on the syllabi how many schools can take pride in organizing time management workshops where students are taught how to use their time productively? Students should be taken through preparing daily 'to do' list, fixing time frames for each activity in the daily routine, prioritizing the tasks and preparing weekly and monthly schedules, cutting off unimportant activities or keeping them for the weekends, keeping a log of the time wasted during a week etc.

1.8. Stress Management: Academic lethargy might be directly related to the stress levels of a student. In schools where student teacher ratio is very low, a change in attitude or behavior would be noticed by the teacher/instructor without delay. But in others, the problem is noticed only when it aggravates and results in academic failure and class retentions. By then, it would have grown into such a situation from where there would be no hope of return. Stress may arise out of simple reasons like inadequate sleep, improper diet or more complicated issues like substance abuse, alcoholism, frustration, lack of a nurturing family atmosphere, unwarranted relationships etc. If students are made aware of these causes and trained on how to handle them, majority of them would be able to manage stress all by themselves. Workshops on stress management would highlight different techniques to handle stress and channelising the energy that's derived from such situations productively.

If every school takes it upon themselves to create awareness on such topics as stress and time management, the academic failures and psychological issues that are now becoming common among high schoolers can be brought down considerably. They would learn to cope with stress and anxiety in a productive rather than destructive way and develop skills to handle stress and tensions in school and personal life.

1.9. Learning Styles: We know that each child is different. So is his learning style. The style that works for me might not work you. A teacher's teaching method is greatly influenced by her learning style. If a child, whose learning style is different from that of the teacher, happens to be in her class, then we can only hope and pray for the child. Most of the instructors are totally unaware of these learning styles and hence find a different style in a student intolerable and blasphemous. A basic test to ascertain one's learning style would categorize a class into visual learners, kinesthetic learners and auditory learners. Each has their own techniques and develops specific mannerisms while learning. We need to understand the ways that we study the best. One might prefer pin drop silence while learning, another might need music to aid him in his learning, one might have to move around while another would find that distractive, one might want to lie down and another would prefer to sit up straight, few others would need a pen or any other object to fiddle with. All this is important to the success of how well we will learn and how well we will take in the information that we are dealing with. 
This awareness would help a teacher to involve all these styles in her lectures thus catering to the needs of all her students. Adequate awareness of these styles would enable each child to adapt his/her skills to fit a variety of learning situations that are different from their style.

1.10. Memory techniques: A very commonly heard complaint from students is that they forget what they have learnt and hence cannot reproduce it on paper. This problem, although may appear simple, is capable of escalating into stress, anxiety and exam phobia.

It is said that mind power can improve memory and it will directly affect academic success. Through memory techniques we can program our mind to delete unnecessary data from it and tune our memory to store selective information. The memory techniques which would help a student are aplenty: the mnemonics technique, use of mind maps, pegging, number/rhyme technique, number/shape technique, the journey system etc. Such techniques would to a great extent facilitate time management and boost a student's confidence.

1.11. Academic coaching: Ability alone cannot garner success. There should be willingness to work towards the goal as well. Academic Coaching is targeted at those students who have the ability to work hard but is clueless/directionless- does not know how to go about it. The problems are more motivational rather than intellectual. A professional coach is assigned to each student to help him in the 'process of learning'. This should not be mistaken for a 'mentor' or MKO as in academic coaching, as the name suggests, coaching is limited to academic lessons alone. The coach would help the student to identify his learning style, determine the learning techniques and strategies best suited for his learning style. He would also be coached on note taking, test preparation, test taking etc.

Academic coaching is basically about crafting a strategy that fits a student with a coach who would keep reminding him about the targets and motivate him when he lags behind.

1.12. Information and Communication Technology: Though earlier ICT was considered only in universities, nowadays most of the schools around the world have started embracing this wholeheartedly. More so because the new improved curriculums demand it. Teachers are equipped with laptops; classrooms have a new addition in the form of overhead projectors. To ensure that introduction of ICT aided learning becomes a sure shot hit certain prerequisites need to be brought in place. Teacher's knowledge, access to ICT tools, time available and adequate training to the teachers to mould their teaching modules into ICT friendly ones. Students would get a hands-on training on using the online resources and on conducting research using these resources. Students will develop skills that will help them in developing their research skills.

Teachers have to encourage students to use ICT to conduct research and to create a final product to share their research findings.

\section{Conclusion}

Thus the bouquet that I suggest includes the above 12 modules. As mentioned before, each child is different and hence his needs for interventions would also be different. For any model to become foolproof, it has to go through an acid test which includes MLI- Measurement, Learning and Improvement.

The initial stages of implementation of this model in schools might bring out areas for improvement which has to be considered and incorporated wherever found necessary. By doing this we can ensure that the model does not become static and goes through a continuous process of improvement.

After all, the basic aim is to assist schools in building an enviable manpower for our nation.

\section{Acknowledgements}

My supervisor, Dr.Harsh Purohit who would not accept anything less than my best efforts. My Husband Sangeeth Ibrahim and my kids Amaan and Jehan, words alone cannot express what I owe them for their encouragement and whose patient love enabled me to complete this article. And to God, who made all things possible.

\section{Articles, Proceedings and Books}

\section{References}

[1] Personal Development Planning Continuing Undergraduate Students, available online at http://ebookbrowse.com/pdp-forcontinuing-ug-students-doc-d143068316,University of Bath, UK

[2] Entwisle, D., \& others. (1986), The schooling process in first grade: Two sample a decade apart, American Educational Research Journal, 23, 587-613.

[3] Goldberg, M. D. (1994), A developmental investigation of intrinsic motivation: Correlates, causes, and consequences in high ability students, doctoral dissertation, University of Virginia, 1994, Dissertation Abstract International, 55-04B, 1688.

[4] Niebuhr, K. (1995): 'The Effect of Motivation on the Relationship of School Climate, Family Environment, and Student Characteristics to Academic Achievement'. Paper presented at the Annual Meeting of the Mid-South Educational Research Association, Biloxi, MS, November 8-10.

[5] Variables affecting student achievement, WEAC, 2005, available online at http://www.weac.org/ resource/primer/variable.htm.

[6] Latham, G. P., \& Locke, E. A. (2007). New developments in and directions for goal-setting research. European Psychologist, vol 12, 290-300

[7] Locke, E. A., \& Latham, G. P, A theory of goal setting and task performance (Englewood Cliffs, NJ: Prentice Hall, 1990).

[8] Herrera, C., Grossman, J.B., Kauh, T.J., Feldman, A.F., \& McMaken, J. (with Jucovy, L.Z.)(2007), Making a difference in schools: The Big Brothers Big Sisters school-based mentoring impact study, Philadelphia, PA: Public/Private Ventures. 